OPEN ACCESS

Edited by:

Dirk Feldmeyer,

Jülich Research Centre, Germany

Reviewed by:

Frank Schmitz,

Saarland University, Germany

Tobias Moser,

University Medical Center Göttingen,

Germany

Wallace B. Thoreson,

University of Nebraska Medical

Center, United States

*Correspondence:

Ulrike Janssen-Bienhold ulrike.janssen.bienhold@

uni-oldenburg.de

Specialty section:

This article was submitted to

Cellular Neurophysiology,

a section of the journal

Frontiers in Cellular Neuroscience

Received: 12 June 2019 Accepted: 03 September 2019

Published: 18 September 2019

Citation:

Nemitz L, Dedek K and Janssen-Bienhold U (2019) Rod

Bipolar Cells Require Horizontal Cells for Invagination Into the Terminals

of Rod Photoreceptors.

Front. Cell. Neurosci. 13:423. doi: 10.3389/fncel.2019.00423

\section{Rod Bipolar Cells Require Horizontal Cells for Invagination Into the Terminals of Rod Photoreceptors}

\author{
Lena Nemitz ${ }^{1}$, Karin Dedek ${ }^{2,3}$ and Ulrike Janssen-Bienhold ${ }^{1,3 *}$ \\ ${ }^{1}$ Visual Neuroscience, Department of Neuroscience, University of Oldenburg, Oldenburg, Germany, ${ }^{2}$ Animal \\ Navigation/Neurosensorics, Institute for Biology and Environmental Sciences, University of Oldenburg, Oldenburg, Germany, \\ ${ }^{3}$ Research Center Neurosensory Science, University of Oldenburg, Oldenburg, Germany
}

In the central nervous system, neuronal processing relies on the precisely orchestrated formation of synapses during development. The first synapse of the visual system is a triad synapse, comprising photoreceptors, horizontal cells and bipolar cells. During the second postnatal week, the axon terminal processes of horizontal cells invaginate rod spherules, followed by rod bipolar cell dendrites. Both elements finally oppose the synaptic ribbon (the release site of glutamate). However, it has not been fully elucidated whether horizontal cells are essential for rod bipolar cell dendrites to find their way into the rod terminal. In the present study, we investigated this question by specifically ablating horizontal cells from the early postnatal mouse retina. We monitored the formation of the rod-to-rod bipolar cell synapse during retinal maturation until postnatal day 21. Based on quantitative electron microscopy, we found that without horizontal cells, the dendrites of rod bipolar cells never entered rod terminals. Furthermore, rods displayed significantly fewer and shorter presynaptic ribbons, suggesting that glutamate release is decreased, which coincided with significantly reduced expression of postsynaptic proteins (mGluR6, GPR179) in rod bipolar cells. Collectively, our findings uncover that horizontal cells are indeed necessary guideposts for rod bipolar cells. Whether horizontal cells release diffusible guidance cues or provide structural guidance by expressing specific cell adhesion molecules remains to be seen.

Keywords: vision, retina, synapse formation, synaptogenesis, ribbon synapse, photoreceptors, horizontal cells, bipolar cells

\section{INTRODUCTION}

The establishment of functional neuronal circuits is crucial for information processing in the central nervous system and requires the formation of precise synaptic connections between different neurons. However, the mechanisms by which specific synapses are assembled are not fully understood.

At the first synapse of the visual system, photoreceptors transfer light information to horizontal cells and bipolar cells. While horizontal cell processes and ON bipolar cell dendrites invaginate into the photoreceptor terminals and form so-called triad synapses, OFF bipolar cells make noninvaginating contacts at the base of the photoreceptor terminal (Haverkamp et al., 2000). In contrast to rod spherules, which are connected to the axon terminals of horizontal cells, cone pedicles are 
contacted by horizontal cell dendrites (Peichl and GonzálezSoriano, 1994). The temporal sequence of triad formation is well described in the mouse retina (Blanks et al., 1974; Rich et al., 1997; Sherry et al., 2003). Rod synaptogenesis is initiated at postnatal day 8 (P8) by the invasion of rod terminals into the outer plexiform layer (OPL). The ribbon, an electron-dense structure surrounded by tethered synaptic vesicles, is attached to the rod membrane and the terminal is contacted by a single horizontal process. Beginning at P9, a second horizontal cell process is recruited and both processes invaginate into the terminal, assuming the positions lateral to the presynaptic ribbon. One day later, one or two ON bipolar cell dendrites start to enter the terminal as the central elements of the triad. Cones synaptogenesis follows the same sequence of events but is initiated 3-4 days earlier. Triad formation is complete for rods and cones by eye opening around P14.

Several studies using knock-out mice have identified molecules that play important roles in the assembly of photoreceptor ribbon synapses. The cell adhesion protein ELFN1, which is expressed in rods, interacts transsynaptically with mGluR6, the glutamate receptor subunit of ON bipolar cells, and is essential for the selective wiring of rods and rod bipolar cells (Cao et al., 2015). Furthermore, rod photoreceptors express SynCAM1, which has also been shown to promote the invagination of $\mathrm{ON}$ bipolar cell dendrites (Ribic et al., 2014). Another crucial element for synapse formation between photoreceptors and $\mathrm{ON}$ bipolar cells is the transsynaptic interaction between the dystroglycan-pikachurin complex of photoreceptors and the orphan receptor GPR179 of ON bipolar cells (Orlandi et al., 2018). Horizontal cells have been reported to express the cell adhesion molecule NGL-2 (Soto et al., 2013, 2018) and the transmembrane semaphorin Sema6A and its receptor PlexinA4 (Matsuoka et al., 2012), which promote horizontal cell invagination into the rod terminal. Moreover, horizontal cells have been shown to help maintaining the triad synapse (Sonntag et al., 2012; Keeley et al., 2013; Wu et al., 2013; Chaya et al., 2017). Two previous studies have attempted to elucidate the role of horizontal cells in the formation of the OPL in the mouse retina. Keeley et al. (2013) revealed that horizontal cells are not essential for the initial targeting of photoreceptor terminals and bipolar cell dendrites to the OPL by using Lim 1 conditional knock-out mice, in which horizontal cells are partially mispositioned to the inner retina. In addition, Wu et al. (2013) reported that photoreceptor terminals of $O c 1$ knock-out mice, that lack $~ 80 \%$ of horizontal cells, contained less invaginations and displayed a loss of the classic triadic organization of postsynaptic processes. These defects were already present at P16, shortly after triad formation is completed in wild-type mice, suggesting that horizontal cells might play an important role in the assembly of photoreceptor ribbon synapses. However, it still remains unclear to which extent synaptic contacts between photoreceptors and ON bipolar cells are formed in the absence of horizontal cells, as the removal of horizontal cells from the OPL has never been complete and synapse assembly has never been studied during development.

In the present study, we investigated the role of horizontal cells in the assembly of the rod-to-rod bipolar cell synapse by specifically ablating horizontal cells from the early postnatal mouse retina via diphtheria toxin receptor (DTR)-mediated cell knock-out. We monitored the formation of the rod synapse in the absence of horizontal cells using quantitative electron microscopy and immunohistochemistry. Our analysis revealed that invaginating (rod) ON bipolar cell dendrites were completely absent from horizontal cell-deficient rod terminals. Furthermore, synaptic ribbon assembly was disrupted and the expression of the postsynaptic proteins mGluR6 and GPR179 at the dendritic tips of rod bipolar cells was strongly reduced. These findings demonstrate that horizontal cells are critical for synapse formation between rods and rod bipolar cells.

\section{MATERIALS AND METHODS}

\section{Animals}

The generation of Cx57-DTRfrtCre mice has been described previously (Sonntag et al., 2012). Cx57-DTRfrtCre mice can be obtained from the European Mouse Mutant Archive. Animals were housed on a $12 \mathrm{~h}$ light/dark cycle with water and food ad libitum. For the experiments, mice of either sex were used. All procedures were performed in accordance with the law on animal protection (Tierschutzgesetz) issued by the German Federal Government and approved by the local animal welfare committee (Niedersächsisches Landesamt für Verbraucherschutz und Lebensmittelsicherheit).

\section{DT Injections}

Control $\left(C x 57^{+/+}\right)$and $C x 57^{+/ D T R}$ mice were injected intraperitoneally with 12.5 to $20 \mathrm{ng}$ diphtheria toxin (DT, Sigma) at P4 and P5.

\section{Tissue Preparation}

Mice were killed by decapitation (P8, P11) or deeply anesthetized with $\mathrm{CO}_{2}$ and killed by cervical dislocation (P15, P21). DT treatment did not affect eye opening around P14 of $\mathrm{C} x 57^{+/+}$ and $C x 57^{+/ D T R}$ mice. Eyes were enucleated and cornea, lens and vitreous body were removed in physiological phosphate buffered saline ( $\mathrm{pH}$ 7.4). For immunohistochemistry, dissected eyecups were fixed in $2 \%$ paraformaldehyde (PFA) and 3\% sucrose in $0.1 \mathrm{M}$ phosphate buffer ( $\mathrm{PB}, \mathrm{pH} 7.4$ ) for $20 \mathrm{~min}$ at room temperature (RT). For electron microscopy, retinae were isolated from the eyecups and fixed in 1\% PFA, 3\% sucrose and $2.5 \%$ glutaraldehyde in $0.05 \mathrm{M} \mathrm{PB}$ overnight at $4{ }^{\circ} \mathrm{C}$, washed in $0.1 \mathrm{M} \mathrm{PB}(3 \times 30 \mathrm{~min})$ and post-fixed in $1 \% \mathrm{OsO}_{4}$ in $0.1 \mathrm{M}$ $\mathrm{PB}$ for $1 \mathrm{~h}$ at RT.

\section{Immunohistochemistry and Image Acquisition}

After fixation, eyecups of $C \times 57^{+/+}(n=3-6$ for each developmental stage) and $C \times 57^{+/ D T R}(n=3-6$ for each developmental stage) mice were washed in $0.1 \mathrm{M} \mathrm{PB}(3 \times 10 \mathrm{~min})$ and cryoprotected with $30 \%$ sucrose in $0.1 \mathrm{M} \mathrm{PB}$ overnight at $4^{\circ} \mathrm{C}$. The following day, tissue was embedded in Tissue-Tek O.C.T. Compound (Sakura Finetek) and sectioned vertically at 
TABLE 1 | List of primary antibodies used in this study.

\begin{tabular}{|c|c|c|c|}
\hline Antibody & Host, type & Dilution & Source, Catalog \#, RRID \\
\hline Calbindin D-28k & Rabbit, polyclonal & $1: 500$ & Swant, CB-38, AB_2721225 \\
\hline Cone arrestin & Rabbit, polyclonal & $1: 1,000$ & Millipore, AB15282, AB_1163387 \\
\hline CtBP2 & Mouse, monoclonal & $1: 5,000$ & BD Biosciences, 612044, AB_399431 \\
\hline $\begin{array}{l}\text { Dihydropyridine-sensitive } \\
\text { calcium channel } \alpha 1 \text { subunit }\end{array}$ & Mouse, monoclonal & $1: 500$ & Millipore, MAB427, AB_2069582 \\
\hline mGluR6 & Sheep, polyclonal & $1: 100$ & Gift from Kirill A. Martemyanov (Cao et al., 2011) \\
\hline $\mathrm{PKC} \alpha$ & Goat, polyclonal & $1: 500$ & R\&D Systems, AF5340, AB_2168552 \\
\hline $\mathrm{PKC} \alpha$ & Mouse, monoclonal & $1: 500$ & Santa Cruz Biotechnology, sc-80, AB_628141 \\
\hline PSD-95 & Mouse, monoclonal & $1: 5,000$ & NeuroMab, 75-028, AB_2307331 \\
\hline
\end{tabular}

$20 \mu \mathrm{m}$ using a Leica CM1860 cryostat. Cryosections were blocked with 5\% ChemiBLOCKER (Millipore), 0.3\% Triton X-100 and $0.02 \% \mathrm{NaN}_{3}$ in $0.1 \mathrm{M} \mathrm{PB}$ for $1 \mathrm{~h}$ at RT and incubated with primary antibodies in blocking solution overnight at $4^{\circ} \mathrm{C}$. A list of primary antibodies is given in Table 1. After washing in $0.1 \mathrm{M} \mathrm{PB}(3 \times 10 \mathrm{~min})$, sections were incubated with secondary antibodies in blocking solution for $2 \mathrm{~h}$ at $\mathrm{RT}$, washed again in $0.1 \mathrm{M} \mathrm{PB}(3 \times 10 \mathrm{~min})$ and mounted in Vectashield (Vector Laboratories). Secondary antibodies used were from donkey or goat and conjugated to either Alexa 488 or Alexa 568 (1:600, Thermo Fisher Scientific).

Images were acquired using a Leica TCS SP8 confocal laser scanning microscope. Scanning was performed with an HC PL APO CS2 $63 \times / 1.4$ oil objective at a resolution of $1024 \times 1024$ pixels and a $z$-axis increment of $0.2 \mu \mathrm{m}$. Maximum projections of collapsed confocal stacks are shown. Brightness and contrast were adjusted using Fiji (Schindelin et al., 2012).

\section{Electron Microscopy}

Fixed retinae were washed in $0.1 \mathrm{M} \mathrm{PB}(3 \times 10 \mathrm{~min})$, dehydrated in a series of 50 to $100 \%$ acetone and incubated in a 1:1 mixture of acetone and Agar 100 Resin (Agar Scientific) for $1 \mathrm{~h}$ at RT. After incubation in pure Agar 100 Resin overnight at RT, embedding medium was hardened for $48 \mathrm{~h}$ at $60^{\circ} \mathrm{C}$. Embedded retinae were cut using a Reichert-Jung Ultracut E ultramicrotome. Semithin sections ( $0.5 \mu \mathrm{m}$ thickness) were collected on slides, stained with $2 \%$ toluidine blue and $0.5 \%$ sodium borate in double-distilled water and examined with a Leica DM6 microscope. Ultrathin sections (90 nm thickness) were collected on copper grids and analyzed using a Zeiss EM 902A electron microscope. Electron micrographs were adjusted in brightness and contrast using Adobe Photoshop CS6 Extended (Adobe Systems).

\section{Quantification and Statistical Analysis}

To quantify the OPL thickness in toluidine blue-stained semithin sections of $C x 57^{+/+}(n=3$ for P8, $n=4$ for P11, $n=5$ for P15, $n=3$ for P21) and $C x 57^{+/ D T R}(n=3$ for P8, $n=4$ for P11, $n=3$ for $\mathrm{P} 15, n=2$ for P21) retinae, we measured the distance from outer nuclear layer (ONL) to inner nuclear layer (INL) somata at 10 locations per animal using the line tool in Fiji. For comparison of rod synaptogenesis in $C x 57^{+/+}(n=4$ for P11, $n=3$ for P15) and $C x 57^{+/ D T R}$ mice ( $n=4$ for P11, $n=5$ for P15), we analyzed between 746 and 1177 rod terminal profiles for each genotype and developmental stage and classified them into four categories: (1) empty terminals (profiles without invaginations), (2) monads (profiles with one invaginating horizontal cell process), (3) dyads (profiles with two invaginating horizontal cell processes) and (4) triads (profiles with at least one invaginating ON bipolar cell dendrite). Rod terminal profiles that could not be clearly assigned to one of these groups were categorized as unclassified. To compare the frequency of rod terminals with and without ribbons between genotypes, the same set of rod terminal profiles was analyzed. For the quantification of ribbon sizes in wild-type $(n=3)$ and horizontal cell-ablated $(n=5)$ retinae at $\mathrm{P} 15$, we measured the length of 30 ribbons per animal using the line tool in Fiji. To compare mGluR6- and GPR179-positive puncta between $C \times 57^{+/+}(n=3)$ and $C \times 57^{+/ D T R}(n=5)$ mice at P15, confocal stacks were deconvolved with a theoretical point spread function using Huygens Essential deconvolution software (SVI) and further processed in Fiji. Background-subtracted single scans were used for the analysis. Intensity thresholds were set manually and kept constant for both experimental groups. Number and average size of puncta were determined for 9 regions of interest $(46.08 \times 25.25 \mu \mathrm{m}$, covering the OPL and proximal ONL) per animal using the Analyze particles function in Fiji. Particles $<0.81$ and $>22.50 \mu \mathrm{m}^{2}$ were excluded from the analysis to prevent the inclusion of noise and stained blood vessels.

Statistical analysis was performed using GraphPad Prism 5 (GraphPad Software). A $p$ value $<0.05$ was considered statistically significant. Data are presented as mean \pm standard deviation (SD).

To compare OPL thickness, ribbon length and the number and average size of mGluR6- and GPR179-positive puncta between $C \times 57^{+/+}$and $C \times 57^{+/ D T R}$ mice, Wilcoxon rank sum test was used. Differences in rod synaptogenesis stages and frequencies of ribbons in rod terminals were analyzed using $\chi^{2}$ test and Fisher's exact test, respectively.

\section{RESULTS}

\section{Early Postnatal Horizontal Cell Ablation Causes Defects in the Development of the OPL}

Previous attempts to ablate horizontal cells during retinal development by intravitreal injection of kainic acid at the 
day of birth (Messersmith and Redburn, 1990) and oncogene expression under the control of the phenylethanolamine $\mathrm{N}$-methyltransferase promoter (Hammang et al., 1993; Peachey et al., 1997) were not cell class-specific and the elimination of horizontal cells from the OPL by knock-out of Lim1 (Poche et al., 2007; Keeley et al., 2013) and Oc1 (Wu et al., 2013) did not affect the whole horizontal cell population. In the rabbit retina, the ablation of horizontal cells alters the segregation of retinal cells into distinct laminae and increases the rodto-cone ratio (Messersmith and Redburn, 1990). To minimize any potential impact of horizontal cell ablation on retinal lamination and cell differentiation, we here ablated horizontal cells after they had migrated to their final position in the distal part of the inner nuclear layer but immediately before their axon terminal processes invaginate into the rod terminal.
For the ablation, we used Cx57-DTRfrtCre mice (Sonntag et al., 2012) that express the primate DTR under the control of the horizontal cell-specific connexin57 (Cx57) promoter and intraperitoneally administered diphtheria toxin (DT) at postnatal day 4 (P4) and P5. To verify the loss of horizontal cells, we labeled retinal cryosections with an antibody against the horizontal cell marker calbindin (Haverkamp and Wässle, 2000). Calbindin immunoreactivity was drastically reduced in horizontal cells at P8 (Figure 1B) and completely absent from the outer retina from P11 onward (Figures 1D,F,H), indicating that the entire cell class was successfully ablated. The gross morphology of calbindin-positive amacrine and ganglion cells was comparable to that in the control (Figures 1A-H), demonstrating that the ablation is specific and restricted to horizontal cells.

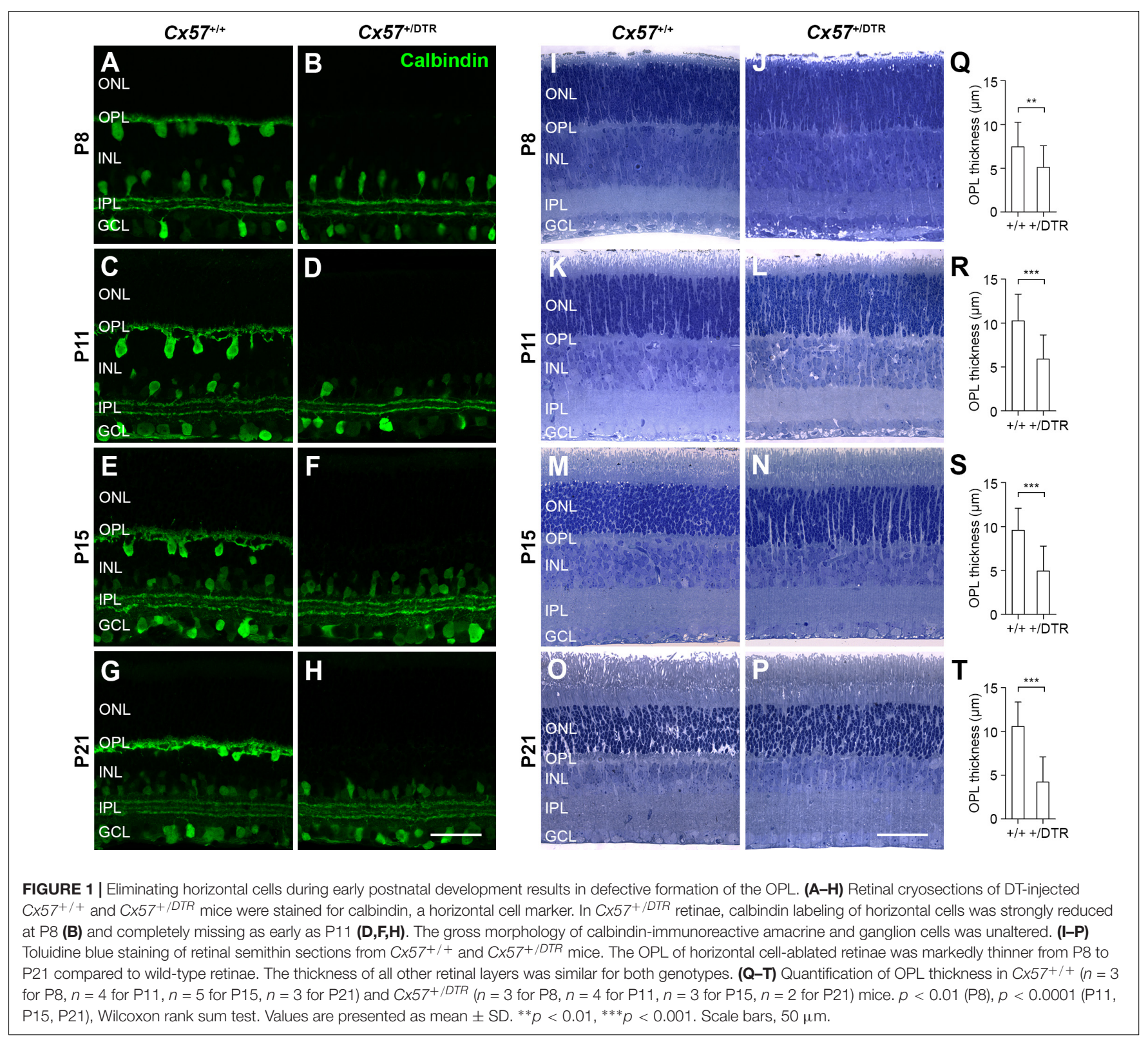


To investigate the effects of early postnatal horizontal cell ablation on the development of the overall morphology of the retina, we stained retinal semithin sections of DT-injected $C \times 57^{+/+}$and $C \times 57^{+/ D T R}$ mice with toluidine blue (Figures 1IP). Compared with wild-type retinae, horizontal cell-ablated retinae showed a significant reduction in the thickness of the OPL between P8 and P21 (Figures 1Q-T; P8: $p<0.01$; P11, P15, P21: $p<0.0001$, Wilcoxon rank sum test), suggesting that the assembly of this layer, which contains the synapses between photoreceptors, horizontal cells and bipolar cells, is defective. By contrast, all other retinal layers were similar in thickness (Figures 1I-P) and labeling for Müller cells with glutamate synthetase did not show any gross differences (Supplementary Figure S1).

\section{Horizontal Cells Are Required for ON Bipolar Cell Invagination in Rods}

To study the role of horizontal cells in the formation of rod synapses, we examined individual rod terminal profiles in the OPL of $C x 57^{+/+}$and $C x 57^{+/ D T R}$ mice by electron microscopy and classified them according to their developmental stage into (1) empty terminals (profiles without invaginations), (2) monads (profiles with one invaginating horizontal cell process), (3) dyads (profiles with two invaginating horizontal cell processes) and (4) triads (profiles with at least one invaginating ON bipolar cell dendrite). For the analysis, two different time points were chosen: P11 (one day after the beginning of triad formation) and P15 (one day after triad formation is complete).

The electron microscopic examination revealed that at P11, the majority of rod terminal profiles from $C \times 57^{+/+}$mice were empty. A substantial portion had invaginations from either one or two horizontal cell processes and only very few terminals already displayed the classic triad configuration at this time point (Figure 2C; 46\% empty, 18\% monads, 23\% dyads, 8\% triads, 5\% unclassified, analysis of 849 rod terminal profiles from $n=4$ mice). By P15, most of the rod terminal profiles in controls contained triads and the percentage of empty terminals was decreased compared to P11, as expected (Figures 2A,C; 27\% empty, $18 \%$ monads, $18 \%$ dyads, $34 \%$ triads, $3 \%$ unclassified, analysis of 746 rod terminal profiles from $n=3$ mice). In contrast, in $C \times 57^{+/ D T R}$ mice, the vast majority of rod terminal profiles did not show any invaginations at either developmental stage. Occasionally, we observed profiles containing remnants from horizontal cells. However, invaginating $\mathrm{ON}$ bipolar cell dendrites were found at a very low frequency and only in terminals with horizontal cell leftovers (Figures 2B,C; P11: 88\% empty, 4\% monads, $2 \%$ dyads, $<1 \%$ triads, $6 \%$ unclassified, analysis of 824 rod terminal profiles from $n=4$ mice; P15: $78 \%$ empty, $8 \%$ monads, $2 \%$ dyads, $<1 \%$ triads, $11 \%$ unclassified, analysis of 1177 rod terminal profiles from $n=5$ mice). The distribution of rod synaptogenesis stages was significantly different between
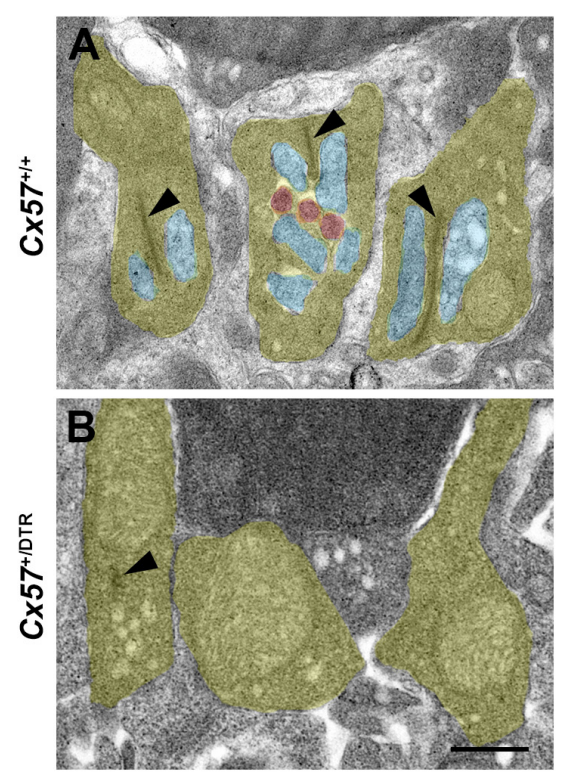

C

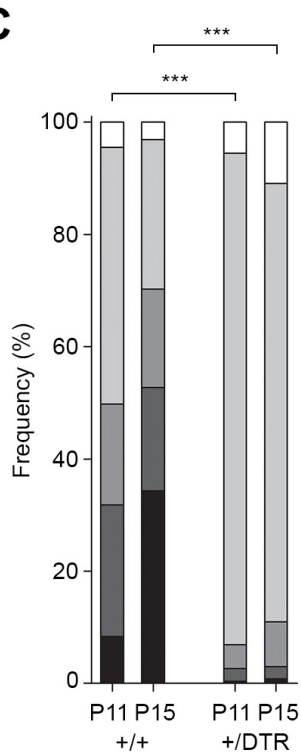

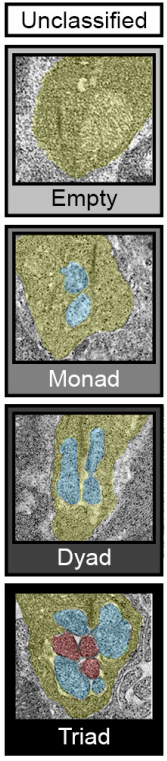

D

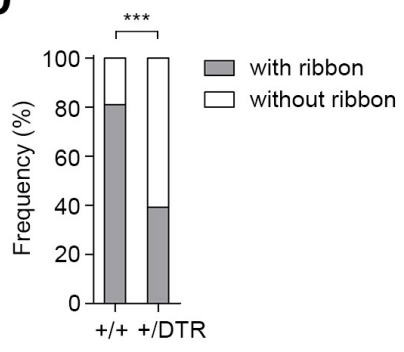

E

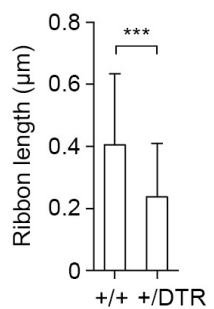

FIGURE 2 | Rod terminals of horizontal cell-ablated mice lack ON bipolar cell invaginations. (A,B) Representative electron micrographs of rod terminals from $\mathrm{C} \times 57^{+/+}$and $\mathrm{C} \times 57^{+/ D T R}$ mice at P15. Rod terminal profiles (yellow) in wild-type retinae showed large presynaptic ribbons (arrowheads) and invaginations from horizontal cells (blue) and ON bipolar cells (red) (A). In contrast, rod terminal profiles in horizontal cell-ablated retinae typically lacked any invaginations. Synaptic ribbons were absent or shorter (arrowhead) (B). (C) Quantification of rod synaptogenesis stages in $C \times 57^{+/+}$and Cx57+/DTR mice at P11 and P15. Between 746 and 1177 rod terminal profiles from wild-type $(n=4$ for P11 and $n=3$ for P15) and Cx57 $+/ D T R$ mice $(n=4$ for P11, $n=5$ for P15) were analyzed for each age. Rod terminal profiles without invaginations were designated as empty, rod terminal profiles with one or two horizontal cell process were designated as monads or dyads, respectively, and rod terminal profiles containing at least one invaginating ON bipolar cell dendrite were designated as triads. $p<0.0001, \chi^{2}$ test. (D) Frequencies of rod terminal profiles with and without ribbons in wild-type $(n=3)$ and horizontal cell-ablated $(n=5)$ retinae. $p<0.0001$, Fisher's exact test. (E) Quantification of ribbon lengths in $C \times 57^{+/+}(n=3)$ and $C \times 57^{+/ D T R}(n=5)$ mice. $p<0.0001$, Wilcoxon rank rum test. Values are presented as mean \pm SD. $* * * p<0.001$. Scale bar, $500 \mu \mathrm{m}$. 
$C x 57^{+/+}$and $C x 57^{+/ D T R}$ mice (P11, P15: $p<0.0001, x^{2}$ test). As we never found a rod terminal profile containing only $\mathrm{ON}$ bipolar dendrites (but no remnants of horizontal cells) at any age, our data strongly indicates that horizontal cells are indispensable for rod bipolar cells to invaginate into rod terminals.

In addition to the lack of invaginating contacts, rod terminal profiles of horizontal cell-ablated mice displayed less presynaptic ribbons at P15 (Figures 2A,B,D; $C \times 57^{+/+}: 81 \%$ with ribbons, $19 \%$ without ribbons, analysis of 746 rod terminal profiles from $n=3$ mice; $C x 57^{+/ D T R}: 39 \%$ with ribbons, $61 \%$ without ribbons, analysis of 1177 rod terminal profiles from $n=5$ mice; $p<0.0001$, Fisher's exact test). If present, ribbons in $C \times 57^{+/ D T R}$ retinae were significantly shorter compared to ribbons in wild-type retinae (Figures 2A,B,E; $C x 57^{+/+}: 0.40 \pm 0.23 \mu \mathrm{m}, n=3$; $C x 57^{+/ D T R}$ : $0.24 \pm 0.17 \mu \mathrm{m}, n=5 ; p<0.0001$, Wilcoxon rank sum test).

\section{Horizontal Cell-Ablated Mice Display a Retraction of Rod Terminals and Disrupted Ribbon Assembly}

The low OPL thickness in $C x 57^{+/ D T R}$ mice (Figures 1J,L,N,P) points to a reduced number of photoreceptor terminals within this layer. To examine their localization in the retina, we stained photoreceptor terminals and cone photoreceptors in $C \times 57^{+/+}$(Figures 3A-D) and $C \times 57^{+/ D T R}$ retinae (Figures 3EH) with antibodies specific for PSD-95 and cone arrestin, respectively, which allowed us to discriminate between rod and cone terminals. At P8, rod spherules were already present in the OPL of $C \times 57^{+/ D T R}$ mice (Figure $3 \mathrm{E}$ ), growing in number until P11 (Figure 3F). This finding is in line with previous studies reporting that horizontal cells are not necessary for targeting of rod terminals to the OPL (Messersmith and Redburn, 1990; Keeley et al., 2013). In addition, we observed an increase in ectopic rod spherules in the ONL between P11 and P21 (Figures 3F-H, arrowheads), demonstrating that rods retract their axon terminals following early postnatal horizontal cell ablation. By contrast, cone terminals generally remained in the OPL (Figures 3E-H).

During photoreceptor synaptogenesis, ribbons are assembled from non-membranous precursor spheres (Regus-Leidig et al., 2009). Our ultrastructural analysis showed that synaptic ribbons were either absent from rod terminals in horizontal cell-ablated mice or shorter when compared to controls (Figures 2B,D,E, arrowhead). To confirm this finding, we labeled retinal sections from $C \times 57^{+/+}$and $C \times 57^{+/ D T R}$ mice for $\mathrm{CtBP} 2$, a ribbon marker, and cone arrestin, which enabled us to distinguish between ribbons of rods and cones. In wild-type retinae, CtBP2 immunolabeling was almost completely confined to the OPL (Figures 3I-L), whereas in horizontal cell-ablated retinae, we frequently found ectopic CtBP2-positive structures in the ONL (Figures 3M-P, arrowheads), in agreement with the retraction of rod terminals we observed. The typical horseshoe shape of the ribbons was clearly visible as early as P15 in the wild-type retina (Figures 3K,K',L). Consistent with the electron microscopic observations, CtBP2 labeling in horizontal cell-ablated mice was rather punctate, even at P15 and P21 (Figures 30,0',P), suggesting that synaptic ribbon assembly is impaired after ablation of horizontal cells. This is in line with earlier reports showing that ribbons are missing or shorter in photoreceptor terminals of horizontal cell-deficient mice (Sonntag et al., 2012; Keeley et al., 2013; Wu et al., 2013).

\section{Recruitment of mGluR6 and GPR179 to the Dendritic Tips of Rod Bipolar Cells Is Impaired in Horizontal Cell-Ablated Mice}

To assess changes on the postsynaptic side, we stained rod bipolar cells with an antibody against protein kinase C alpha (PKC $\alpha)$ and components of the ON bipolar cell signaling complex with antibodies against the metabotropic glutamate receptor mGluR6 and $\mathrm{Ca}_{v}$ 1.1. The latter cross-reacts with GPR179 (Hasan et al., 2016), a $G$ protein-coupled receptor serving as a membrane anchor for regulators of G-protein signaling (Orlandi et al., 2012). During retinal development, $\mathrm{ON}$ bipolar cell dendrites emerge from neuroepithelial-like processes that terminate at the outer limiting membrane (Morgan et al., 2006). By P8, rod bipolar cells from wild-type mice had already established a dendritic network in the OPL and rod bipolar cell dendritic tips were decorated with some mGluR6-immunoreactive puncta (Figure 4A). The number and size of mGluR6-positive puncta increased until the retina reached maturity at P21 (Figures 4A-D). GPR179 immunoreactivity was first detectable in the developing OPL at P15 (Figures 4I-L). Compared to wild-type mice, rod bipolar cell dendrites from $C \times 57^{+/ D T R}$ mice were less branched and showed progressive sprouting into the ONL. Furthermore, the expression of mGluR6 and GPR179 in rod bipolar cell processes was greatly reduced throughout development (Figures $4 \mathbf{E}-\mathbf{H}, \mathbf{M}-\mathbf{P}$ ). We quantified this for P15 and found the number and average size of mGluR6- and GPR170-positive puncta significantly reduced in horizontal cell-ablated mice (Table 2). Thus, our data suggest that postsynaptic targeting of mGluR6 cascade-related elements to the dendritic tips of rod bipolar cells is compromised in the absence of horizontal cells, potentially because glutamatergic input from photoreceptors is impaired.

\section{DISCUSSION}

In this study, we investigated the role of horizontal cells in the formation of the rod photoreceptor synapse by ablating horizontal cells from the early postnatal mouse retina. Our immunohistochemical and electron microscopic analysis revealed that in the absence of horizontal cells (1) ON bipolar cells were not able to invaginate into rod terminals, (2) presynaptic ribbon assembly was disrupted and (3) postsynaptic accumulation of mGluR6 signaling complex components in ON bipolar cells was impaired. These results demonstrate that horizontal cells are indispensable for the assembly of the rod-torod bipolar cell synapse (Figure 5).

Keeley et al. (2013) investigated the role of horizontal cells in the formation and maintenance of the OPL using Lim 1 conditional knock-out mice, in which horizontal cells are partially mislocalized in the inner retina. Consistent with our results, this study revealed that horizontal cells are not necessary for the initial targeting of photoreceptor terminals and bipolar 


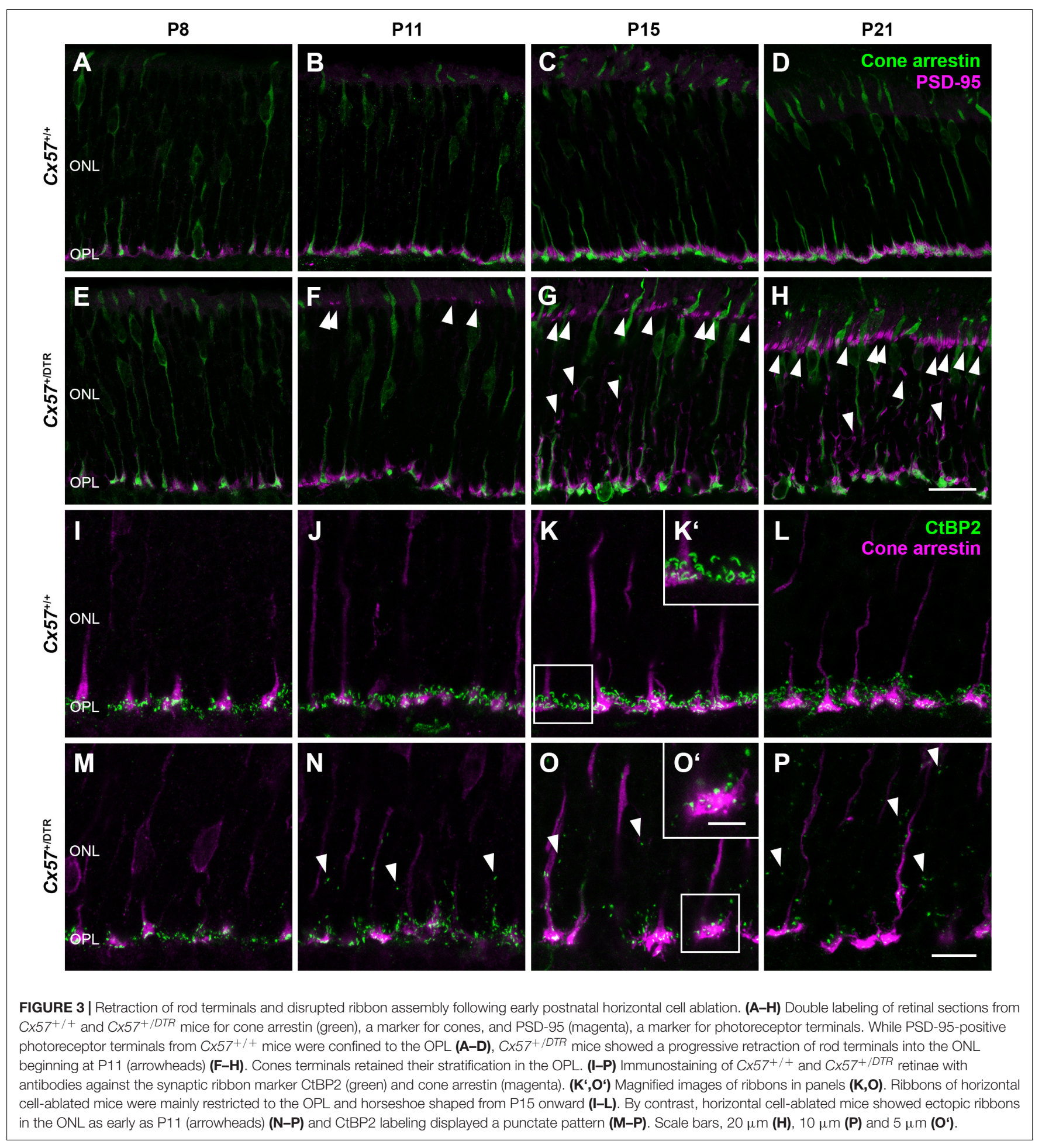

cell dendrites to the OPL but for the maintenance of this layer. A study by Wu et al. (2013) showed that the knock-out of the homeodomain transcription factor $O c 1$ results in a loss of $\sim 80 \%$ of the horizontal cell population. Comparable to $C x 57^{+/ D T R}$ mice, $O c 1$ knock-out mice displayed fewer and shorter ribbons, which were rarely recruited to the plasma membrane. Moreover, photoreceptor terminals did not show the stereotypic triad organization at P16 and P30. However, some invaginations of postsynaptic processes were present in rod and cone terminals, likely because $\sim 20 \%$ of horizontal cells are still formed in $O c 1$ knock-out mice. In addition to that, it has been shown that also long-term removal of horizontal cells from the adult retina leads 


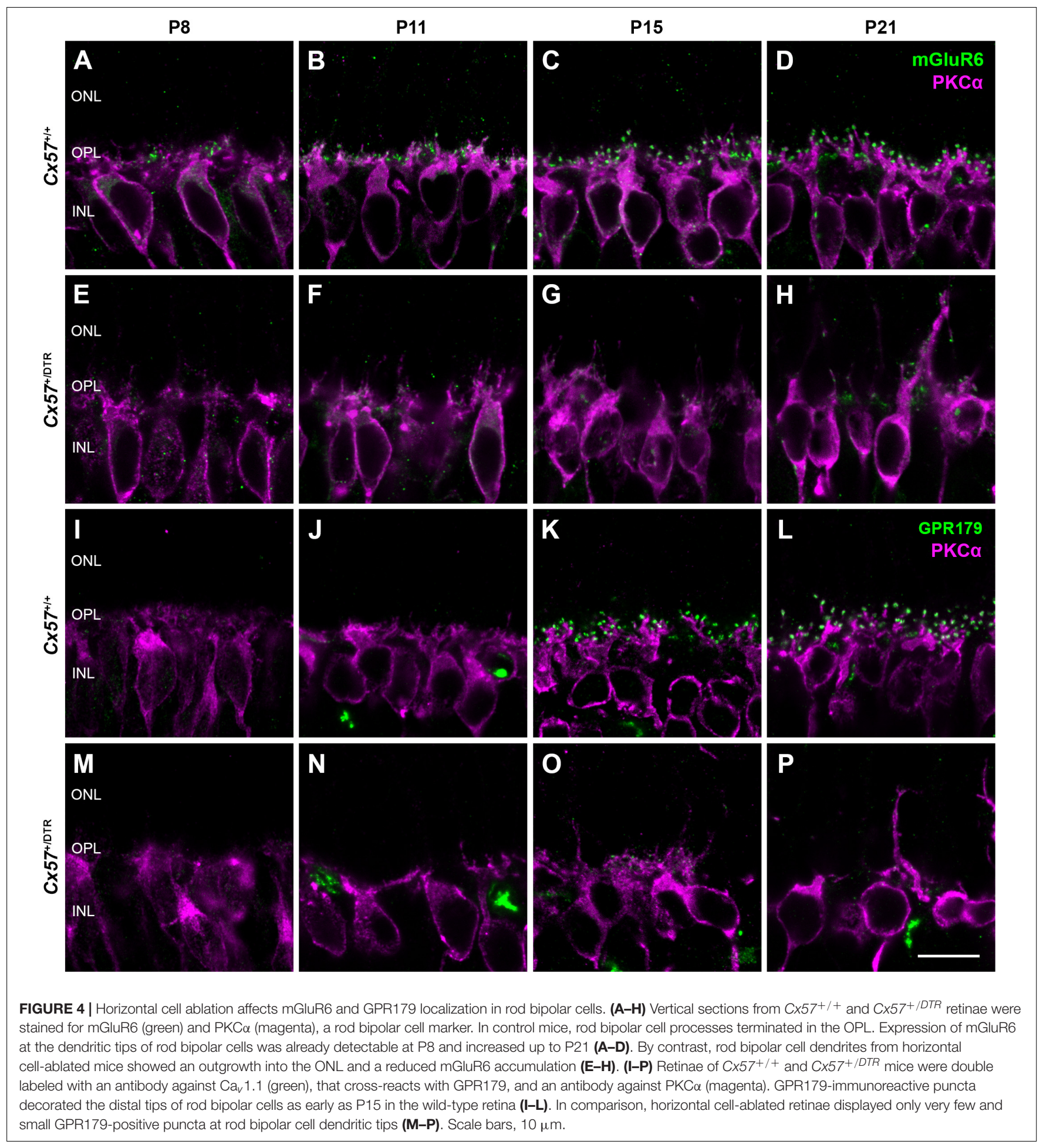

to a disruption of triad synapses and remodeling in the outer retina (Sonntag et al., 2012; Chaya et al., 2017). Thus, horizontal cells are not only essential for the formation (this study), but also for the maintenance of synaptic contacts between rods and rod bipolar cells (Sonntag et al., 2012; Keeley et al., 2013; Wu et al., 2013; Chaya et al., 2017).
But why are rod bipolar cells not able to find their way into the rod terminal in the absence of horizontal cells? We consider three mechanisms by which horizontal cells may contribute to synapse formation between rods and rod bipolar cells. First, horizontal cells may release guidance cues that direct pathfinding of rod bipolar cell dendrites. Earlier studies have shown that glial cells 
TABLE 2 | Quantification of mGluR6- and GPR179-positive puncta in Cx57+/+ and Cx57+/DTR mice at P15.

\begin{tabular}{|c|c|c|c|}
\hline & $C \times 57^{+/+}($mean \pm SD $)$ & $C \times 57^{+/ D T R}($ mean $\pm \mathrm{SD})$ & $p$ value \\
\hline Number of mGluR6-postive puncta per $100 \mu \mathrm{m}$ & $93.7 \pm 25.4$ & $26.14 \pm 16.0$ & $<0.0001$ \\
\hline Average size of mGluR6-positive puncta (in $\mu \mathrm{m}^{2}$ ) & $0.12 \pm 0.03$ & $0.08 \pm 0.02$ & $<0.0001$ \\
\hline Number of GPR179-positive puncta per $100 \mu \mathrm{m}$ & $82.9 \pm 25.6$ & $36.5 \pm 27.5$ & $<0.0001$ \\
\hline Average size of GPR179-positive puncta (in $\mu \mathrm{m}^{2}$ ) & $0.12 \pm 0.03$ & $0.07 \pm 0.01$ & $<0.0001$ \\
\hline
\end{tabular}

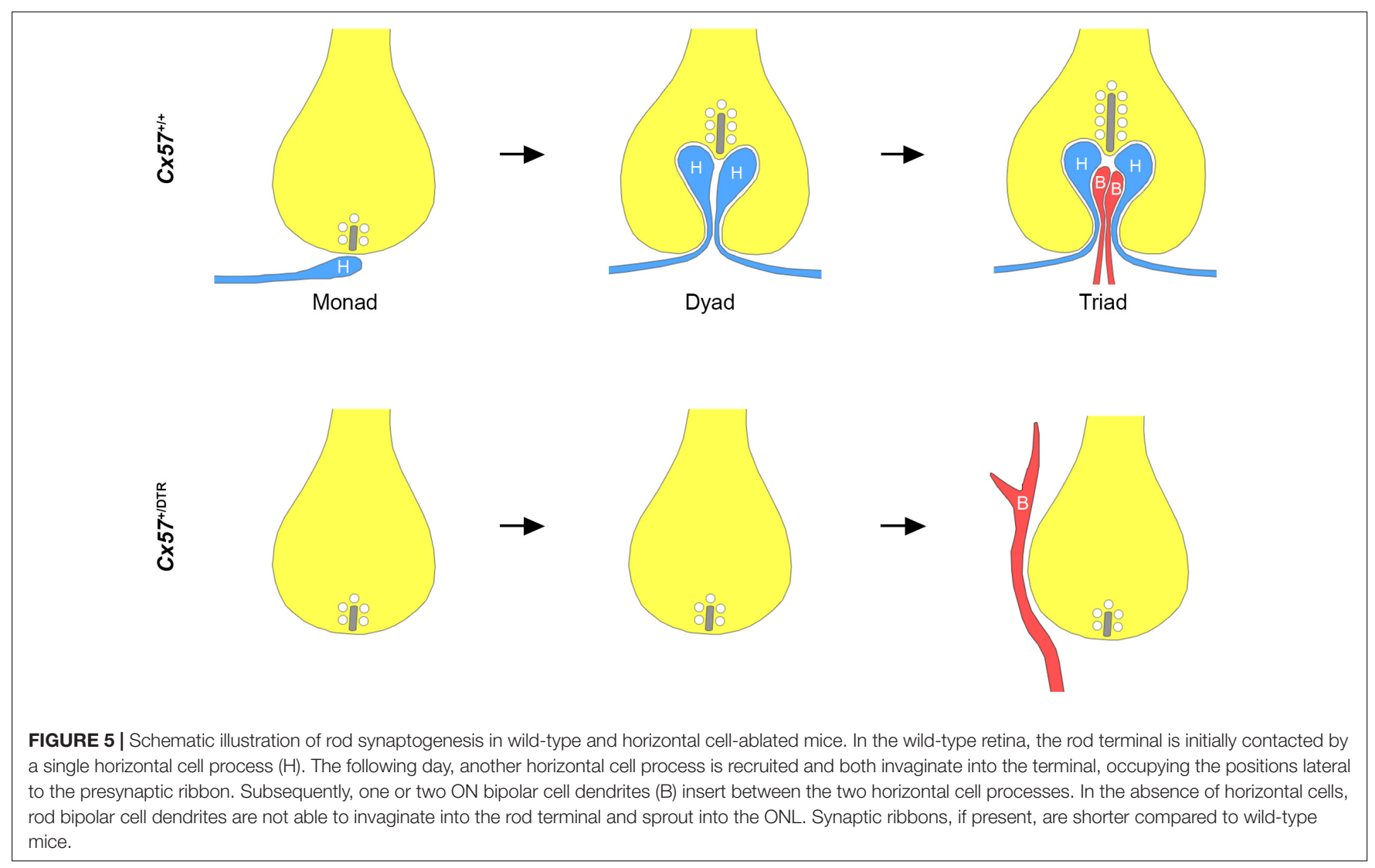

provide attractive and repellant cues and act as guidepost cells and intermediate targets for neurons (reviewed in Chotard and Salecker, 2004). As Müller cells, the most abundant retinal glial cells, are among the last cell types born during neurogenesis (Young, 1985; Rapaport et al., 2004), horizontal cells possibly take over this function of glial cells in the developing retina.

Second, horizontal cells may provide structural guidance for rod bipolar cell dendrites to invaginate into the rod terminal by expressing specific cell adhesion molecules. This hypothesis is supported by the finding that emerging bipolar cell dendrites in and outside the OPL are closely associated with processes from horizontal cells in the first postnatal week (Morgan et al., 2006). Moreover, it has been reported that rod bipolar cell dendrites grow along and co-fasciculate with sprouting horizontal cell processes in CNGA3/CNGB1 double knock-out (Michalakis et al., 2013) and bassoon mutant mice (Specht et al., 2009). In horizontal cells, only a few cell adhesion molecules have been identified so far. NGL-2 localizes to horizontal cell axons, directs their laminar targeting and promotes synapse formation between rods and horizontal cells (Soto et al., 2013, 2018). However, in NGL-2-deficient mice, photoreceptor terminals and bipolar cell dendrites stratify normally and photoreceptor ribbon synapses are formed, albeit at a lower frequency (Soto et al., 2013), indicating that this molecule is not responsible for the developmental defects we observed in horizontal cell-ablated mice. In addition, $\mathrm{N}$-cadherin has been shown to be important for horizontal cell dendrite morphogenesis and synapse formation in the chicken retina (Tanabe et al., 2006) but it remains to be tested whether $\mathrm{N}$-cadherin also plays a role in synaptogenesis the mouse retina. Apart from that, it is possible that horizontal cells influence the expression of cell adhesion or extracellular matrix proteins in rod photoreceptors, such as ELFN1 (Cao et al., 2015), SynCAM1 (Ribic et al., 2014) or the dystroglycan-pikachurin complex (Sato et al., 2008; Omori et al., 2012; Orlandi et al., 2018), that promote the invagination of rod bipolar cells.

Third, disturbed neurotransmission in the outer retina may impede synapse formation between rods and rod bipolar cells in horizontal cell-ablated mice. Horizontal cells receive 
glutamatergic input from photoreceptors and provide feedback signals to photoreceptors (Mangel, 1991; Wu, 1991; Thoreson et al., 2008; Jackman et al., 2011) and feedforward signals to bipolar cells (Yang and Wu, 1991; Fahey and Burkhardt, 2003). Different mechanisms have been proposed for horizontal cell feedback: hemichannel-mediated ephaptic feedback (Kamermans, 2001), pH-mediated feedback (Hirasawa and Kaneko, 2003), GABA-mediated feedback (Wu, 1992) and a combination of all three (Kemmler et al., 2014). Feedforward signaling to bipolar cells possibly involves GABA (Puller et al., 2014). Several studies have reported that neurotransmission is important for the maturation and maintenance of photoreceptor ribbon synapses. Similar to horizontal cell ablation, mutations in presynaptic proteins such as bassoon (Dick et al., 2003; Specht et al., 2009), CAST (tom Dieck et al., 2012), CaBP4 (Haeseleer et al., 2004), Ca 1.4 (Mansergh et al., 2005; Chang et al., 2006; Bayley and Morgans, 2007; Liu et al., 2013; Zabouri and Haverkamp, 2013) and CNGA3/CNGB1 (Michalakis et al., 2013) that regulate glutamate release from photoreceptors cause a loss of synaptic contacts in the OPL, a retraction of rod terminals and sprouting of horizontal and bipolar cell processes. This may be caused by a lack of synaptic transmission and/or lack of horizontal cell signals. However, when the light-dependent modulation of feedback and feedforward signals from horizontal cells is abolished, this has no effects on the structure of the rod-torod bipolar cell synapse (Ströh et al., 2018). Also, the elimination of GABA synthesis in horizontal cells does not prevent the assembly of photoreceptor ribbon synapses (Schubert et al., 2010), arguing against a direct involvement of horizontal cell signaling in synapse formation or maintenance.

Whether horizontal cells are not only essential for rod synapse formation, but also for cone synapse formation remains to be seen. As cone synaptogenesis is initiated 3-4 days prior to rod synaptogenesis (Rich et al., 1997; Sherry et al., 2003) (at the same time we induced the horizontal cell ablation by DT injections), our approach is not suitable to investigate the assembly of the cone-to-ON bipolar cell synapse in the absence of horizontal cells. In contrast to rod spherules, which are invaginated by the axon terminals of horizontal cells, cone pedicles are invaginated by horizontal cell dendrites (Peichl and González-Soriano, 1994). Thus, synapse assembly might be differently regulated for both photoreceptor types. However, ribbon structures and postsynaptic recruitment of mGluR6 signaling complex components seemed equally affected in the rod and cone pathway, suggesting that horizontal cells may also be critical for cone synapse formation.

Although further investigations are needed to identify the underlying mechanism, our study demonstrates that horizontal

\section{REFERENCES}

Bayley, P. R., and Morgans, C. W. (2007). Rod bipolar cells and horizontal cells form displaced synaptic contacts with rods in the outer nuclear layer of the nob2 retina. J. Comp. Neurol. 500, 286-298. doi: 10.1002/cne.21188

Blanks, J. C., Adinolfi, A. M., and Lolley, R. N. (1974). Synaptogenesis in the photoreceptor terminal of the mouse retina. J. Comp. Neurol. 156, 81-93. doi: 10.1002/cne.901560107 cells are essential for presynaptic photoreceptor maturation, invagination of rod bipolar cells into rods and postsynaptic recruitment of $\mathrm{ON}$ bipolar cell signaling components in the outer retina.

\section{DATA AVAILABILITY}

All datasets generated for this study are included in the manuscript and/or the Supplementary Files.

\section{ETHICS STATEMENT}

The animal study was reviewed and approved by Niedersächsisches Landesamt für Verbraucherschutz und Lebensmittelsicherheit.

\section{AUTHOR CONTRIBUTIONS}

UJ-B performed DT injections and tissue preparation. LN performed immunohistochemistry, image acquisition, electron microscopy, quantification and statistical analysis, prepared the figures, and wrote a first draft of the manuscript. All authors designed the experiments and contributed to the interpretation of data. KD and UJ-B revised the manuscript.

\section{FUNDING}

This work was supported by the Deutsche Forschungsgemeinschaft (grant DE1154/3-1 to KD and UJ-B, and Research Training Group 1885/1-2 stipend to LN).

\section{ACKNOWLEDGMENTS}

We would like to thank Bettina Kewitz for excellent technical assistance. We also thank Kirill A. Martemyanov for the kind gift of the mGluR6 antibody.

\section{SUPPLEMENTARY MATERIAL}

The Supplementary Material for this article can be found online at: https://www.frontiersin.org/articles/10.3389/fncel. 2019.00423/full\#supplementary-material

Cao, Y., Posokhova, E., and Martemyanov, K. A. (2011). TRPM1 forms complexes with nyctalopin in vivo and accumulates in postsynaptic compartment of onbipolar neurons in mGluR6-dependent manner. J. Neurosci. 31, 11521-11526. doi: 10.1523/JNEUROSCI.1682-11.2011

Cao, Y., Sarria, I., Fehlhaber, K. E., Kamasawa, N., Orlandi, C., James, K. N., et al. (2015). Mechanism for selective synaptic wiring of rod photoreceptors into the retinal circuitry and its role in vision. Neuron 87, 1248-1260. doi: 10.1016/j.neuron.2015.09.002 
Chang, B., Heckenlively, J. R., Bayley, P. R., Brecha, N. C., Davisson, M. T., Hawes, N. L., et al. (2006). The nob2 mouse, a null mutation in Cacnalf: anatomical and functional abnormalities in the outer retina and their consequences on ganglion cell visual responses. Vis. Neurosci. 23, 11-24. doi: 10.1017/ S095252380623102X

Chaya, T., Matsumoto, A., Sugita, Y., Watanabe, S., Kuwahara, R., Tachibana, M., et al. (2017). Versatile functional roles of horizontal cells in the retinal circuit. Sci. Rep. 7:5540. doi: 10.1038/s41598-017-05543-2

Chotard, C., and Salecker, I. (2004). Neurons and glia: team players in axon guidance. Trends Neurosci. 27, 655-661. doi: 10.1016/j.tins.2004. 09.001

Dick, O., tom Dieck, S., Altrock, W. D., Ammermüller, J., Weiler, R., Garner, C. C., et al. (2003). The presynaptic active zone protein bassoon is essential for photoreceptor ribbon synapse formation in the retina. Neuron 37, 775-786. doi: 10.1016/S0896-6273(03)00086-2

Fahey, P. K., and Burkhardt, D. A. (2003). Center-surround organization in bipolar cells: symmetry for opposing contrasts. Vis. Neurosci. 20, 1-10. doi: 10.1017/ S0952523803201012

Haeseleer, F., Imanishi, Y., Maeda, T., Possin, D. E., Maeda, A., Lee, A., et al. (2004). Essential role of Ca2+-binding protein 4, a Cav1.4 channel regulator, in photoreceptor synaptic function. Nat. Neurosci. 7, 1079-1087. doi: 10.1038/ nn 1320

Hammang, J. P., Behringer, R. R., Baetge, E. E., Palmiter, R. D., and Messing, A. (1993). Oncogene expression in retinal horizontal cells of transgenic mice results in a cascade of neurodegeieration. Neuron 10, 1197-1209. doi: 10.1016/ 0896-6273(93)90067-2

Hasan, N., Ray, T. A., and Gregg, R. G. (2016). CACNA1S expression in mouse retina: novel isoforms and antibody cross-reactivity with GPR179. Vis. Neurosci. 33:E009. doi: 10.1017/S0952523816000055

Haverkamp, S., Grünert, U., and Wässle, H. (2000). The cone pedicle, a complex synapse in the retina. Neuron 27, 85-95. doi: 10.1016/S0896-6273(00)00011-8

Haverkamp, S., and Wässle, H. (2000). Immunocytochemical analysis of the mouse retina. J. Comp. Neurol. 424, 1-23. doi: 10.1002/1096-9861(20000814)424:1<1:: aid-cnel $>3.3 . c 0 ; 2-\mathrm{m}$

Hirasawa, H., and Kaneko, A. (2003). pH changes in the invaginating synaptic cleft mediate feedback from horizontal cells to cone photoreceptors by modulating Ca 2+ channels. J. Gen. Physiol. 122, 657-671. doi: 10.1085/jgp.200308863

Jackman, S. L., Babai, N., Chambers, J. J., Thoreson, W. B., and Kramer, R. H. (2011). A positive feedback synapse from retinal horizontal cells to cone photoreceptors. PLoS Biol. 9:e1001057. doi: 10.1371/journal.pbio.1001057

Kamermans, M. (2001). Hemichannel-mediated inhibition in the outer retina. Science 292, 1178-1180. doi: 10.1126/science.1060101

Keeley, P. W., Luna, G., Fariss, R. N., Skyles, K. A., Madsen, N. R., Raven, M. A., et al. (2013). Development and plasticity of outer retinal circuitry following genetic removal of horizontal cells. J. Neurosci. 33, 17847-17862. doi: 10.1523/ JNEUROSCI.1373-13.2013

Kemmler, R., Schultz, K., Dedek, K., Euler, T., and Schubert, T. (2014). Differential regulation of cone calcium signals by different horizontal cell feedback mechanisms in the mouse retina. J. Neurosci. 34, 11826-11843. doi: 10.1523/ JNEUROSCI.0272-14.2014

Liu, X., Kerov, V., Haeseleer, F., Majumder, A., Artemyev, N., Baker, S. A., et al. (2013). Dysregulation of Ca v 1.4 channels disrupts the maturation of photoreceptor synaptic ribbons in congenital stationary night blindness type 2. Channels 7, 514-523. doi: 10.4161/chan.26376

Mangel, S. C. (1991). Analysis of the horizontal cell contribution to the receptive field surround of ganglion cells in the rabbit retina. J. Physiol. 442, 211-234. doi: 10.1113/jphysiol.1991.sp018790

Mansergh, F., Orton, N. C., Vessey, J. P., Lalonde, M. R., Stell, W. K., Tremblay, F., et al. (2005). Mutation of the calcium channel gene Cacnalf disrupts calcium signaling, synaptic transmission and cellular organization in mouse retina. Hum. Mol. Genet. 14, 3035-3046. doi: 10.1093/hmg/ddi336

Matsuoka, R. L., Jiang, Z., Samuels, I. S., Nguyen-Ba-Charvet, K. T., Sun, L. O., Peachey, N. S., et al. (2012). Guidance-cue control of horizontal cell morphology, lamination, and synapse formation in the mammalian outer retina. J. Neurosci. 32, 6859-6868. doi: 10.1523/JNEUROSCI.0267-12.2012

Messersmith, E. K., and Redburn, D. A. (1990). Kainic acid lesioning alters development of the outer plexiform layer in neonatal rabbit retina. Int. J. Dev. Neurosci. 8, 447-461. doi: 10.1016/0736-5748(90)90077-F
Michalakis, S., Schäferhoff, K., Spiwoks-Becker, I., Zabouri, N., Koch, S., Koch, F., et al. (2013). Characterization of neurite outgrowth and ectopic synaptogenesis in response to photoreceptor dysfunction. Cell. Mol. Life Sci. 70, 1831-1847. doi: $10.1007 / \mathrm{s} 00018-012-1230-\mathrm{Z}$

Morgan, J. L., Dhingra, A., Vardi, N., and Wong, R. O. L. (2006). Axons and dendrites originate from neuroepithelial-like processes of retinal bipolar cells. Nat. Neurosci. 9, 85-92. doi: 10.1038/nn1615

Omori, Y., Araki, F., Chaya, T., Kajimura, N., Irie, S., Terada, K., et al. (2012). Presynaptic dystroglycan-pikachurin complex regulates the proper synaptic connection between retinal photoreceptor and bipolar cells. J. Neurosci. 32, 6126-6137. doi: 10.1523/JNEUROSCI.0322-12.2012

Orlandi, C., Omori, Y., Wang, Y., Cao, Y., Ueno, A., Roux, M. J., et al. (2018). Transsynaptic Binding of orphan receptor GPR179 to dystroglycan-pikachurin complex is essential for the synaptic organization of photoreceptors. Cell Rep. 25, 130-145. doi: 10.1016/j.celrep.2018.08.068

Orlandi, C., Posokhova, E., Masuho, I., Ray, T. A., Hasan, N., Gregg, R. G., et al. (2012). GPR158/179 regulate G protein signaling by controlling localization and activity of the RGS7 complexes. J. Cell Biol. 197, 711-719. doi: 10.1083/ jcb.201202123

Peachey, N. S., Roveri, L., and McCall, M. A. (1997). Functional consequences of oncogen-induced horizontal cell degeneration in the retinas of transgenic mice. Vis. Neurosci. 144, 627-632. doi: 10.1017/s0952523800012591

Peichl, L., and González-Soriano, J. (1994). Morphological types of horizontal cell in rodent retinae: a comparison of rat, mouse, gerbil, and guinea pig. Vis. Neurosci. 11, 501-517. doi: 10.1017/s095252380000242x

Poche, R. A., Kwan, K. M., Raven, M. A., Furuta, Y., Reese, B. E., and Behringer, R. R. (2007). Lim1 is essential for the correct laminar positioning of retinal horizontal cells. J. Neurosci. 27, 14099-14107. doi: 10.1523/JNEUROSCI.404607.2007

Puller, C., Haverkamp, S., Neitz, M., and Neitz, J. (2014). Synaptic elements for GABAergic feed-forward signaling between HII horizontal cells and blue cone bipolar cells are enriched beneath primate S-cones. PLoS One 9:e88963. doi: 10.1371/journal.pone.0088963

Rapaport, D. H., Wong, L. L., Wood, E. D., Yasumura, D., and LaVail, M. M. (2004). Timing and topography of cell genesis in the rat retina. J. Comp. Neurol. 474, 304-324. doi: 10.1002/cne.20134

Regus-Leidig, H., tom Dieck, S., Specht, D., Meyer, L., and Brandstätter, J. H. (2009). Early steps in the assembly of photoreceptor ribbon synapses in the mouse retina: the involvement of precursor spheres. J. Comp. Neurol. 512, 814-824. doi: 10.1002/cne.21915

Ribic, A., Liu, X., Crair, M. C., and Biederer, T. (2014). Structural organization and function of mouse photoreceptor ribbon synapses involve the immunoglobulin protein synaptic cell adhesion molecule 1: SynCAM 1 organizes ribbon synapses. J. Comp. Neurol. 522, 900-920. doi: 10.1002/cne.23452

Rich, K. A., Zhan, Y., and Blanks, J. C. (1997). Migration and synaptogenesis of cone photoreceptors in the developing mouse retina. J. Comp. Neurol. 388, 47-63. doi: 10.1002/(sici)1096-9861(19971110)388:1<47::aid-cne4>3.3.co;2-h

Sato, S., Omori, Y., Katoh, K., Kondo, M., Kanagawa, M., Miyata, K., et al. (2008). Pikachurin, a dystroglycan ligand, is essential for photoreceptor ribbon synapse formation. Nat. Neurosci. 11, 923-931. doi: 10.1038/nn.2160

Schindelin, J., Arganda-Carreras, I., Frise, E., Kaynig, V., Longair, M., Pietzsch, T., et al. (2012). Fiji: an open-source platform for biological-image analysis. Nat. Methods 9, 676-682. doi: 10.1038/nmeth.2019

Schubert, T., Huckfeldt, R. M., Parker, E., Campbell, J. E., and Wong, R. O. (2010). Assembly of the outer retina in the absence of GABA synthesis in horizontal cells. Neural Dev. 5:15. doi: 10.1186/1749-8104-5-15

Sherry, D. M., Wang, M. M., Bates, J., and Frishman, L. J. (2003). Expression of vesicular glutamate transporter 1 in the mouse retina reveals temporal ordering in development of rod vs. cone and ON vs. OFF circuits. J. Comp. Neurol. 465, 480-498. doi: 10.1002/cne.10838

Sonntag, S., Dedek, K., Dorgau, B., Schultz, K., Schmidt, K.-F., Cimiotti, K., et al. (2012). Ablation of retinal horizontal cells from adult mice leads to rod degeneration and remodeling in the outer retina. J. Neurosci. 32, 10713-10724. doi: 10.1523/JNEUROSCI.0442-12.2012

Soto, F., Watkins, K. L., Johnson, R. E., Schottler, F., and Kerschensteiner, D. (2013). NGL-2 regulates pathway-specific neurite growth and lamination, synapse formation, and signal transmission in the retina. J. Neurosci. 33, 11949-11959. doi: 10.1523/JNEUROSCI.1521-13.2013 
Soto, F., Zhao, L., and Kerschensteiner, D. (2018). Synapse maintenance and restoration in the retina by NGL2. eLife 7:e30388. doi: 10.7554/eLife.30388

Specht, D., Wu, S.-B., Turner, P., Dearden, P., Koentgen, F., Wolfrum, U., et al. (2009). Effects of presynaptic mutations on a postsynaptic Cacnals calcium channel colocalized with mGluR6 at mouse photoreceptor ribbon synapses. Invest. Ophthamol. Vis. Sci. 50, 505-515. doi: 10.1167/iovs.08-2758

Ströh, S., Puller, C., Swirski, S., Hölzel, M.-B., van der Linde, L. I. S., Segelken, J., et al. (2018). Eliminating glutamatergic input onto horizontal cells changes the dynamic range and receptive field organization of mouse retinal ganglion cells. J. Neurosci. 38, 2015-2028. doi: 10.1523/JNEUROSCI.014117.2018

Tanabe, K., Takahashi, Y., Sato, Y., Kawakami, K., Takeichi, M., and Nakagawa, S. (2006). Cadherin is required for dendritic morphogenesis and synaptic terminal organization of retinal horizontal cells. Development 133, 4085-4096. doi: 10. 1242/dev.02566

Thoreson, W. B., Babai, N., and Bartoletti, T. M. (2008). Feedback from horizontal cells to rod photoreceptors in vertebrate retina. J. Neurosci. 28, 5691-5695. doi: 10.1523/JNEUROSCI.0403-08.2008

tom Dieck, S., Specht, D., Strenzke, N., Hida, Y., Krishnamoorthy, V., Schmidt, K.-F., et al. (2012). Deletion of the presynaptic scaffold CAST reduces active zone size in rod photoreceptors and impairs visual processing. J. Neurosci. 32, 12192-12203. doi: 10.1523/JNEUROSCI.075212.2012

Wu, F., Li, R., Umino, Y., Kaczynski, T. J., Sapkota, D., Li, S., et al. (2013). Onecut1 is essential for horizontal cell genesis and retinal integrity. J. Neurosci. 33, 13053-13065. doi: 10.1523/JNEUROSCI.0116-13.2013
Wu, S. M. (1991). Input-output relations of the feedback synapse between horizontal cells and cones in the tiger salamander retina. J. Neurophysiol. 65, 1197-1206. doi: 10.1152/jn.1991.65.5.1197

Wu, S. M. (1992). Feedback connections and operation of the outer plexiform layer of the retina. Curr. Opin. Neurobiol. 2, 462-468. doi: 10.1016/0959-4388(92) 90181-J

Yang, X. L., and Wu, S. M. (1991). Feedforward lateral inhibition in retinal bipolar cells: input-output relation of the horizontal cell-depolarizing bipolar cell synapse. Proc. Natl. Acad. Sci. U.S.A. 88, 3310-3313. doi: 10.1073/pnas.88. 8.3310

Young, R. W. (1985). Cell differentiation in the retina of the mouse. Anat. Rec. 212, 199-205. doi: 10.1002/ar.1092120215

Zabouri, N., and Haverkamp, S. (2013). Calcium channel-dependent molecular maturation of photoreceptor synapses. PLoS One 8:e63853. doi: 10.1371/ journal.pone.0063853

Conflict of Interest Statement: The authors declare that the research was conducted in the absence of any commercial or financial relationships that could be construed as a potential conflict of interest.

Copyright (C) 2019 Nemitz, Dedek and Janssen-Bienhold. This is an open-access article distributed under the terms of the Creative Commons Attribution License (CC BY). The use, distribution or reproduction in other forums is permitted, provided the original author(s) and the copyright owner(s) are credited and that the original publication in this journal is cited, in accordance with accepted academic practice. No use, distribution or reproduction is permitted which does not comply with these terms. 